\title{
Correction to: Introducing Students of Color to Health Sciences Research: An Evaluation of the Health Disparities Summer Internship Program
}

\author{
Nicole A. McLean ${ }^{1,2} \cdot$ Marilyn Fraser $^{2,3} \cdot$ Nicole A. Primus ${ }^{2,3} \cdot$ Michael A. Joseph $^{1,2}$ \\ Published online: 4 July 2018 \\ ๑) Springer Science+Business Media, LLC, part of Springer Nature 2018 \\ Correction to: Journal of Community Health \\ https://doi.org/10.1007/s10900-018-0505-1
}

The original version of this article unfortunately contained a mistake. The funding source (grant number) information was missing in the original version of the article.

The correct information is given below.

Funding This project was funded by the National Institute on Minority Health and Health Disparities (5P20MD006875-04).

The original article can be found online at https://doi.org/10.1007/ s10900-018-0505-1.

Nicole A. McLean

nicole.mclean@bison.howard.edu

1 Department of Epidemiology and Biostatistics, School of Public Health, SUNY Downstate Medical Center, Brooklyn, NY, USA

2 Brooklyn Health Disparities Center, Brooklyn, NY, USA

3 Arthur Ashe Institute for Urban Health, Brooklyn, NY, USA 